\title{
PELATIHAN BAHAN AJAR DENGAN PENDEKATAN SCIENCE, TECHNOLOGY, ENGINEERING AND MATHEMATICS UNTUK GURU MATEMATIKA DI KECAMATAN PALASAH
}

\author{
Nia Kania, Erik Santoso, Vici Suciawati \\ Program Studi Pendidikan Matematika, FKIP, Universitas Majalengka, Indonesia \\ niakania@unma.ac.id
}

\begin{abstract}
The problem of learning mathematics cannot be separated from the teacher's style in implementing learning. In addition to the style of the media teacher, it must also increase the ability to think critically and creatively. Efforts that can be used to improve the learning process through making teaching materials by asking for STEM. The STEM approach integrates Science, Technology, Engineering and Mathematics in one learning that is carried out by the teacher. The dedication was held for two days, 4-5 February 2020. The location of the activity in SDN Weragati I, Palasah, Majalengka with elementary school participants in Palasah, Majalengka. In conclusion STEM is suitable to be used to lure students to be active in class and conduct experiments in learning to find concepts that are being learned. Through this training there was an increase in the understanding of trainees about STEM teaching materials by 32\% very good, 55\% good and the remaining $13 \%$ answered enough. This activity can be followed up with training for further evaluation activities after the teacher carries out the learning process with STEM in their respective schools
\end{abstract}

Keywords: Teaching Material, STEM

\begin{abstract}
Abstrak
Permasalahan pembelajaran matematika tidak lepas dari gaya guru dalam melaksanakan pembelajaran. Selain gaya guru media yang digunakan juga harus mampu meningkatkan kemampuan berpikir kritis dan kreatif. Upaya yang dapat digunakan untuk memperbaiki proses pembelajaran adalah melalui pembuatan bahan ajar dengan pendekatan STEM. Pendekatan STEM mengintegrasikan Science, Technology, Engineering and Mathematics dalam satu pembelajaran yang dilaksanakan oleh guru. Pengabdian ini dilaksanakan Pelaksanaan selama dua hari yaitu tanggal 4-5 Februari 2020. Lokasi kegiatan di SDN Weragati I Kecamatan Palasah, Kabupaten Majalengka dengan peserta SD di Kecamaatan Palasah Kabupaten Majalengka. Kesimpulannya Pendekatan STEM cocok untuk digunakan untuk memancing siswa agar aktif di kelas dan melakukan eksperimen dalam pembelajaran untuk menemukan konsep yang sedang dipelajari. Melalui kegiatan ini adanya peningkatan pemahaman peserta pelatihan mengenai bahan ajar STEM sebesar 32\% sangat baik, 55\% baik dan sisanya 13\% menjawab cukup. Kegiatan ini dapat ditindaklanjuti dengan pelatihan kegiatan evaluasi selanjutnya setelah guru melaksanakan proses pembelajaran dengan pendekatan STEM di sekolahnya masing-masing
\end{abstract}

Kata kunci: Bahan Ajar, STEM

\section{Pendahuluan}

Kualitas pembelajaran merupakan peningkatan kemampuan pemahaman siswa dari yang tidak bisa menjadi bisa. Peningkatan kualitas pembelajaran di peruntukan bagi guru yang melakukan inovasi dalam pembelajaran. Hal ini sesuai dengan pendapat bahwa guru memliki perang yang penting di masyarakat untuk meningkatkan kualitas pendidikan sesuai dengan tuntutan zaman (Megasari, 2014). Berdasarkan pendapat tersebut maka guru memiliki peran yang penting dalam peningkatan Sumber Daya Manusia (SDM) 
melalui kegiatan pendidikan yang diselenggarakan di sekolah. Matematika memiliki peran penting dalam pendidikan dan teknologi. Hal ini didasarkan bahwa matematika adalah rajanya dari segala ilmu sehingga mendapat julukan the queen of science. Hal ini sesuai dengan pendapat bahwa matematika memiliki peranan pentin dan perkembangan ilmu yang lainnya (Putra \& Anggraini, 2016) (Yusnita, Irda, Maskur, \& Suherman, 2016).

Memiliki peranan penting dalam perkembangan teknologi tidak lantas membuat matematika disenangi oleh siswa. Hal ini dasarkan beberapa pendapat bahwa matematika masih dianggap sulit (Fadholi \& Waluya, 2015) (Fitriasari, 2017). Pendapat tersebut dapat terjawab salah satunya dengan nilai ujian nasional matematika memiliki rata-rata di bawah dari nilai mata pelajaran lainnya. Kemudian didukung juga di lapang melalui wawancara dengan guru di Sekolah Dasar yang ada di Kecamatan Palasah, diantara permasalahannya diungkap oleh seorang guru "sesah pisan ngajarkeun matematika mah barudakna saresah nerap". Melihat permasalahan, penting untuk guru agar dapat melaksanakan pembelajaran yang dapat merubah paradigma mata pelajaran matematika dari pelajar yang sukar menjadi pembelajaran yang mudah dan menyenangkan. Perlu peran serta dari semua stekholder, baik guru, kepala sekolah sampai dengan orang tua untuk membantu siswa dalam belajar matematika. Oleh karena itu, ini menjadi pemikiran untuk semua bahwa inovasi dalam pembelajaran matematika mesti selalu dilakukan untuk mencapai kualitas pembelajaran yang ideal.

Pada hakikatnya proses pembelajaran dibagi menjadi tiga fase yaitu sebelum pembelajaran (perencanaan pembelaejaran), saat pembelajaran dan setelah pembelajaran (Suryadi, 2013). Inovasi pembelajaran dimulai saat guru merencanakan pembelajaran. Inovasi dalam pembelajaran dapat dilakukan oleh guru melalui penggunaan pembelajaran yang dapat memancing siswa untuk aktiv di kelas. Inovasi tersebut bisa diaplikasikan dalam konteks penggunaan media yang sederhana, ini artinya bahwa setiap guru dapat melakukannya. Inovasi tersebut diarahkan pada pengalaman siswa belajar dadlam bentuk yang nyata. Hal ini sesuai dengan pendapat "penting kiranya siswa dalam belajar diberikan keleluasaan dalam mendapatkan pemahaman melalui aktivitas yang sifatnya pengamatan dan eksperimen yang dilakukan" (Ismayani, 2016).

Salah satu pembelajaran yang mampu memfasilitasi siswa dalam melakukan penemuan adalah dengan pembelajaran melalui pendekatan Science, Technology, Engineering, and Mathematics (STEM). STEM bermula di Amerika Serikat dan didasari laporan-laporan studi yang menunjukkan terjadi kekurangan kandidat untuk mengisi lapangan kerja dalam bidang-bidang STEM serta raihan siswa sekolah menengah AS dalam TIMSS dan PISA (Roberts, 2012). STEM bukan berati memisahkan Science, Technology, Engineering, and Mathematics tetapi justru menggabungkan keempat dalam suatu pembelajaran yang memfokuskan pendidikan dalam pemecahan masalah di dunia nyata maupun profesi sehingga peserta didik dapat bersaing dalam era ekonomi baru yang berbasis pengetahuan (National STEM Education, 2014) (Reeve, 2013). Melalui pembelajaran dengan pendekatan STEM diharapkan semua siswa mampu mengaplikasikan pengetahuan dalam konteks dunia nyata yang dapat digunakan untuk memecahkan masalahnya. STEM dapat terlaksana dengan baik jika guru sebelumnya menyiapkan dengan baik bahan ajar yang dengan mengadopsi pendekatan STEM. Melalui 
bahan ajar guru dapat melakukan perancangan yang sangat sistematis agar pembelajaran dengan pendekatan STEM dapat dilakukan dengan baik.

Tim pelaksana pengabdian sepakat untuk melaksanakan sebuah bentuk pengabdian yang akan diberikan kepada guru guru yang di SD Se-Kecamatan Palasah melalui pelatihan STEM dalam pembelajaran matematika. Hal ini didasari karena tim ingin memberikan kontribusi agar guru yang menjadi sasaran dalam pelaksanaan STEM tersebut dapat mengaplikasikan STEM dalam pelaksanaan pembelajarannya. STEM sangat menunjang untuk guru dalam proses pembelajaran yang bersifat penemuan. Hal ini juga diperkuat oleh penelitian mengenai Pendekatan Science, Technology, Engineering And Mathematics (STEM) Sebagai Alternatif Dalam Mengembangkan Minat Belajar Peserta Didik Sekolah Dasar dengan hasil penelitian Hasil kegiatan pelatihan menunjukkan tingkat keberhasilan dengan indikasi kesesuaian material dengan kebutuhan guru SDN Hasil kegiatan pelatihan menunjukkan tingkat keberhasilan dengan indikasi kesesuaian material dengan kebutuhan guru SDN (Sukmana, 2018). Melalui pemaparan masalah tersebut maka tim sepakat untuk melaksanakan pengabdian pada guru SD di Kecamatan Palasah dengan tujuan agar guru memahami mengenai pendekatan, bahan ajar STEM dan mampu mengimplementasikannya dalam proses pembelajaran di kelas.

\section{Metode}

Pelaksanaan pengabdian ini didasarkan pada permasalahan yang mendasari adanya kegiatan ini dengan tujuan adanya pemahaman yang menyeluruh serta pengaplikasian konsep pembelajaran STEM dalam pembelajaran di kelas. Lokasi kegiatan di SDN Weragati I Kecamatan Palasah, Kabupaten Majalengka dengan peserta SD di Kecamaatan Palasah Kabupaten Majalengka. Pelaksanaan ini didasarkan pada tiga tahapan yaitu perencanaan, pelaksanaan dan evaluasi. Tahap perencanaan merupakan tahap awal mulai dari melakukan kordinasi antara tim, P3M Universitas Majalengka dengan mitra pengabdian dan selanjutnya menentukan tanggal pelaksanaannya. Pelaksanaan dilaksanakan selama dua hari yaitu tanggal 4-5 Februari 2020. Pelaksanaan hari pertama fokus pada pemahaman mengenai STEM serta praktik pembelajaran STEM dan hari keduanya praktik pembelajaran STEM di sekolahnya masing-masing. Tahap evaluasi dilakukan setelah pelaksanaan pelatihan dengan melibatkan peserta.

\section{Hasil dan Pembahasan}

Pelaksanaan kegiatan pengabdian ini dilaksanakan oleh tim pengabdian dari Universitas Majalengka yang terdiri dari tiga orang. Sesuai dengan kesepakatan bahwa pelaksanaan kegiatan dilaksanakan di Sekretariat Gugus SDN Weragati I Kecamatan Palasah, Kabupaten Majalengka dengan perserta terdiri dari kelas atas SD di wilayah tersebut yaitu kelas IV dan Kelas V. Ada 22 orang peserta yang mengikuti pelatihan yang terdiri dari 8 sekolah. Sebelum acara dimulai dilakukan registrasi untuk seluruh peserta. Registrasi dapat terlihat pada gambar di bawah ini 


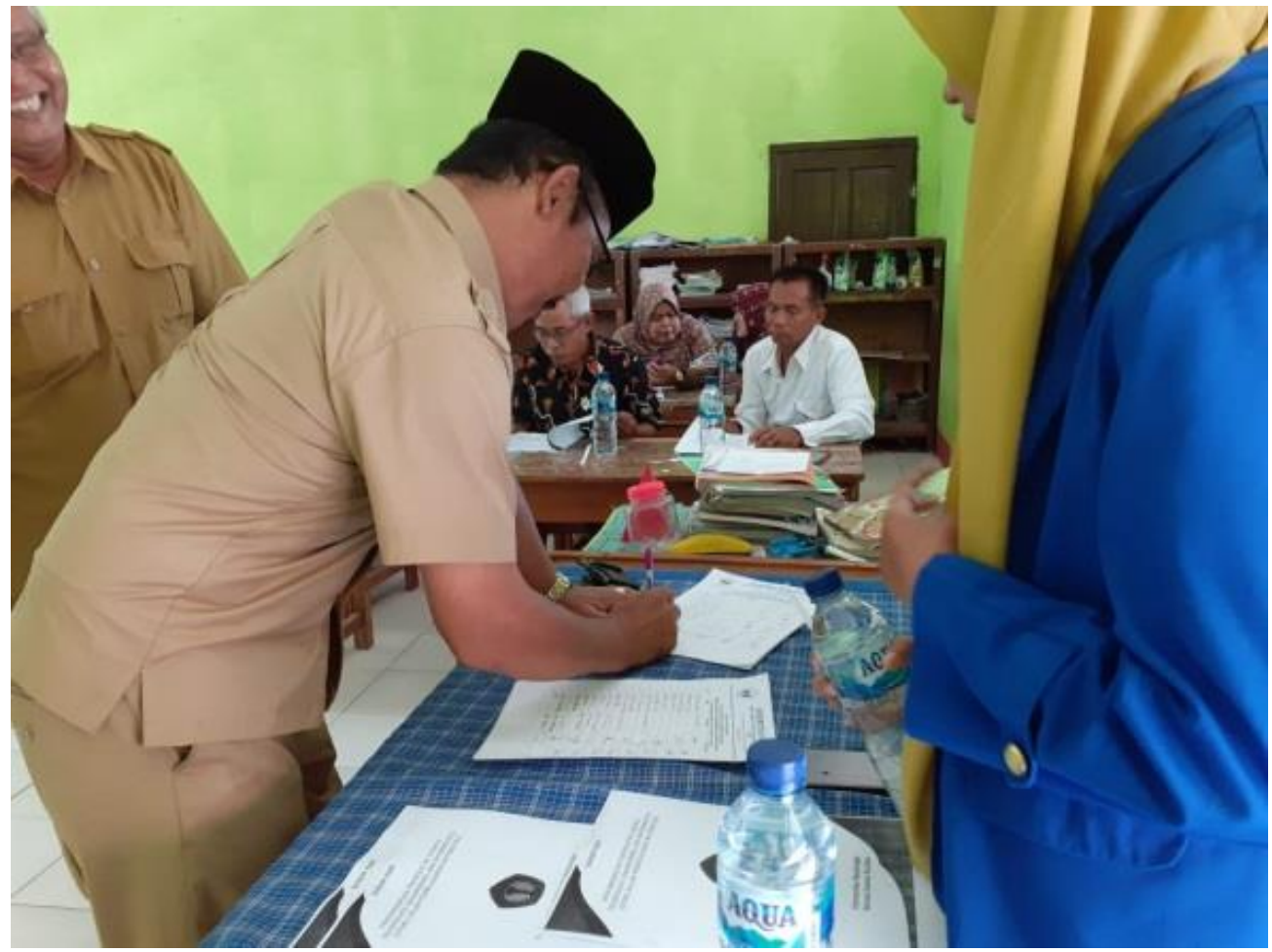

Gambar 1 Pengawas Pembina

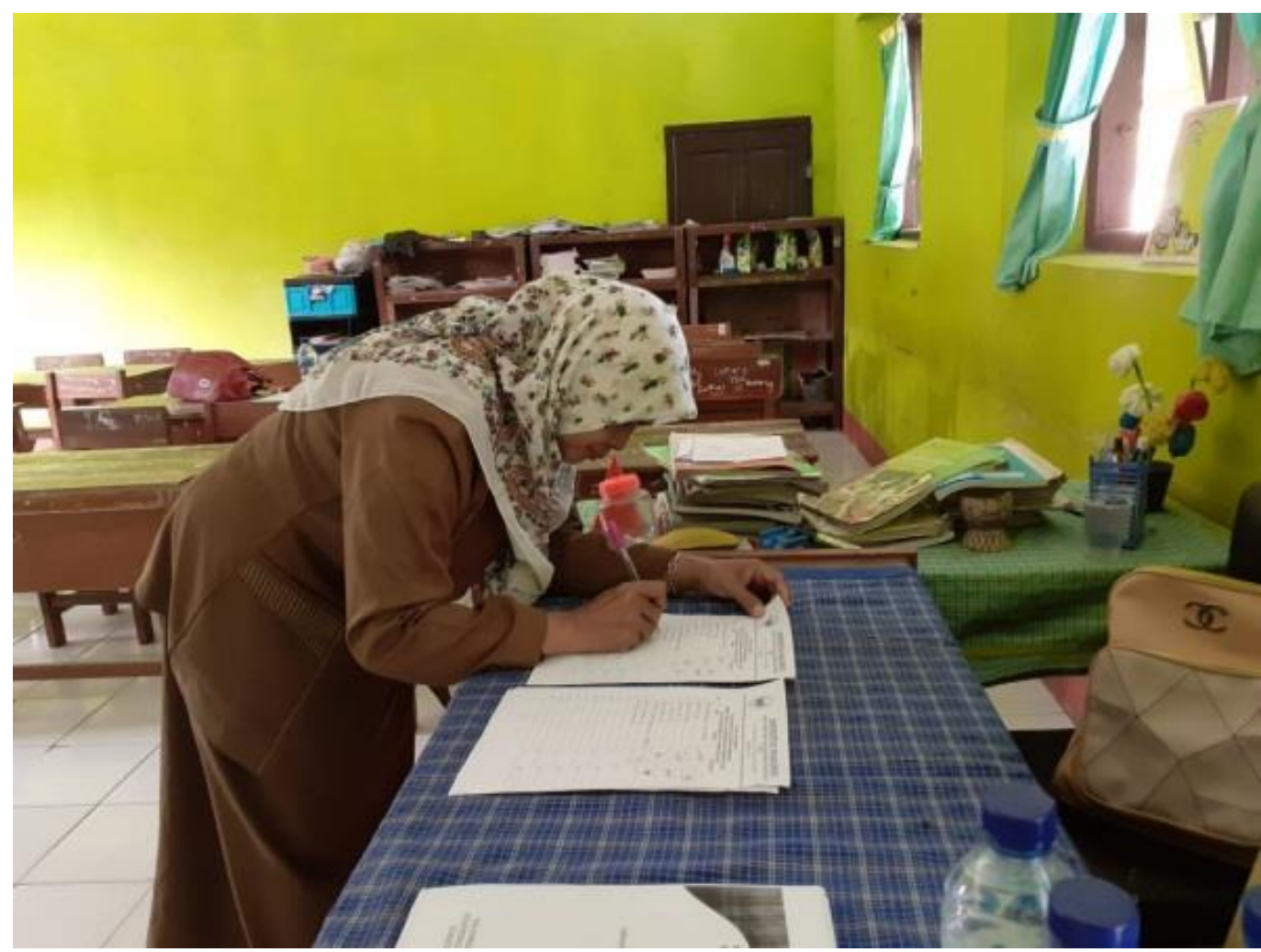

Gambar 2 Registrasi Peserta Pelatihan

Setelah registrasi dilaksanakan maka pelaksanaan kegiatan dimulai dengan pembukaan yang dapat tergambarkan pada gambar di bawah ini: 


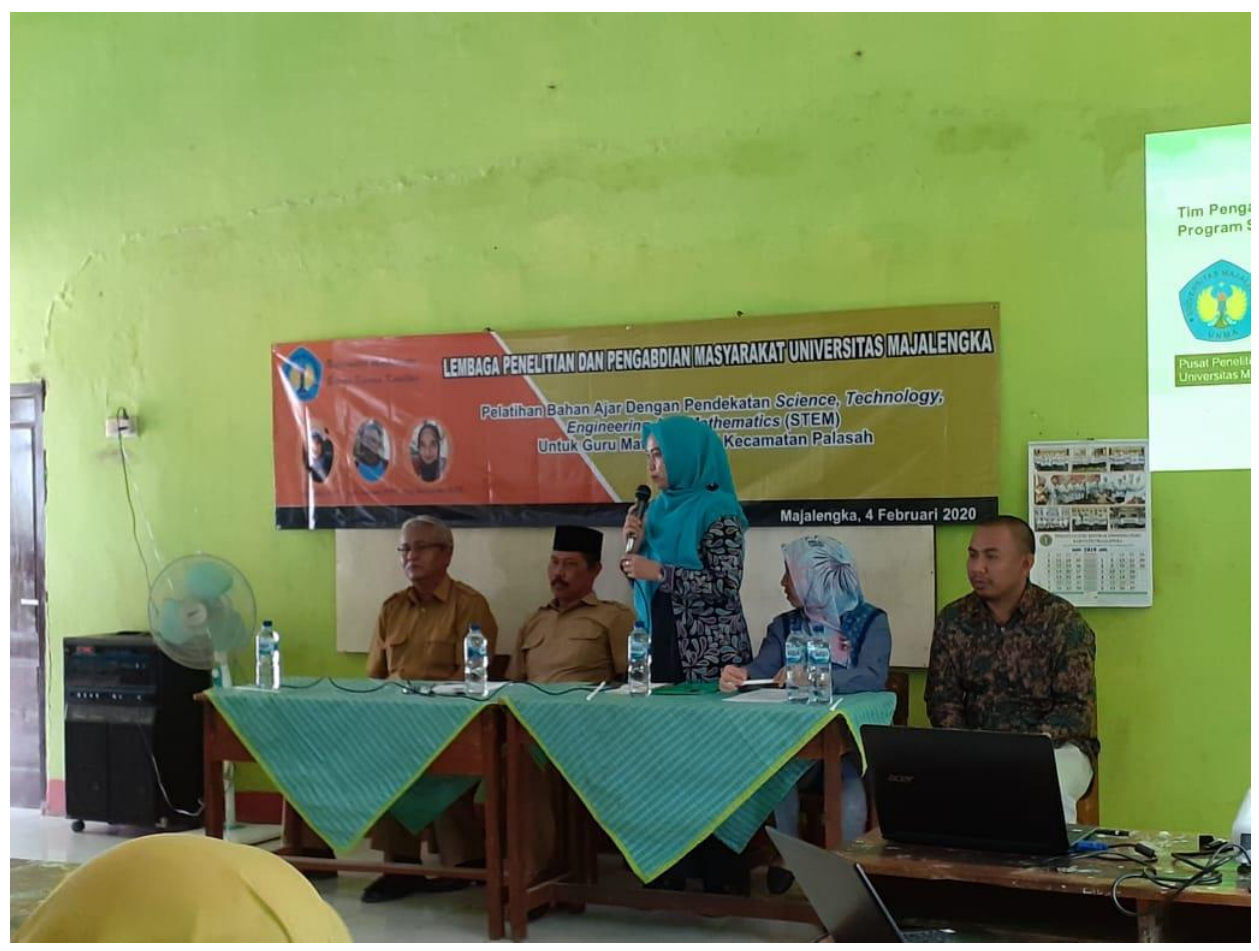

Gambar 3 Kegiatan Pembukaan

Kegiatan pembukaan dilakukan tepat pada pukul 08.30 dan dihadiri perwakilan dari P3M Universitas Majalengka, kemudian mitra dan dibukai secara resmi oleh pengwas satuan pendidikan. Setelah kegiatan pembukaan dilaksanakan kemudian acara dilanjutkan pada pamaparan inti mengenai STEM. Seluruh peserta memgang modul yang sudah dipersiapkan oleh tim pengabdian. Penyampaian materi dibagi menjadi tiga sesi sesuai dengan materi yang disajikan Nia Kania, M.Pd. memaparkan mengenai sejarah dan pentingnya STEM dalam pembelajaran, kemudian Vici Suciawati, M.Pd. memaparkan mengenai langkah-langkah STEM dalam pembelajaran dan Erik Santoso, M.Pd. memaparkan mengenai praktik STEM dalam pembelajaran di sekolah dasar. Kegiatan pelaksanaan dapat digambarakan sebgai berikut:
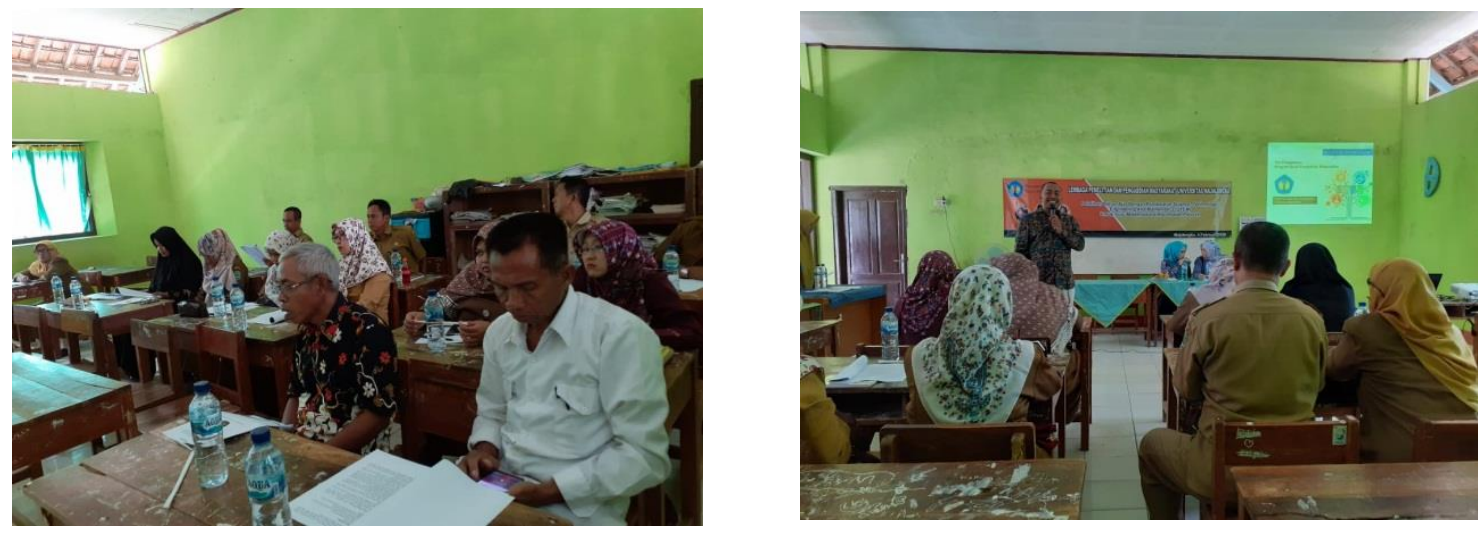

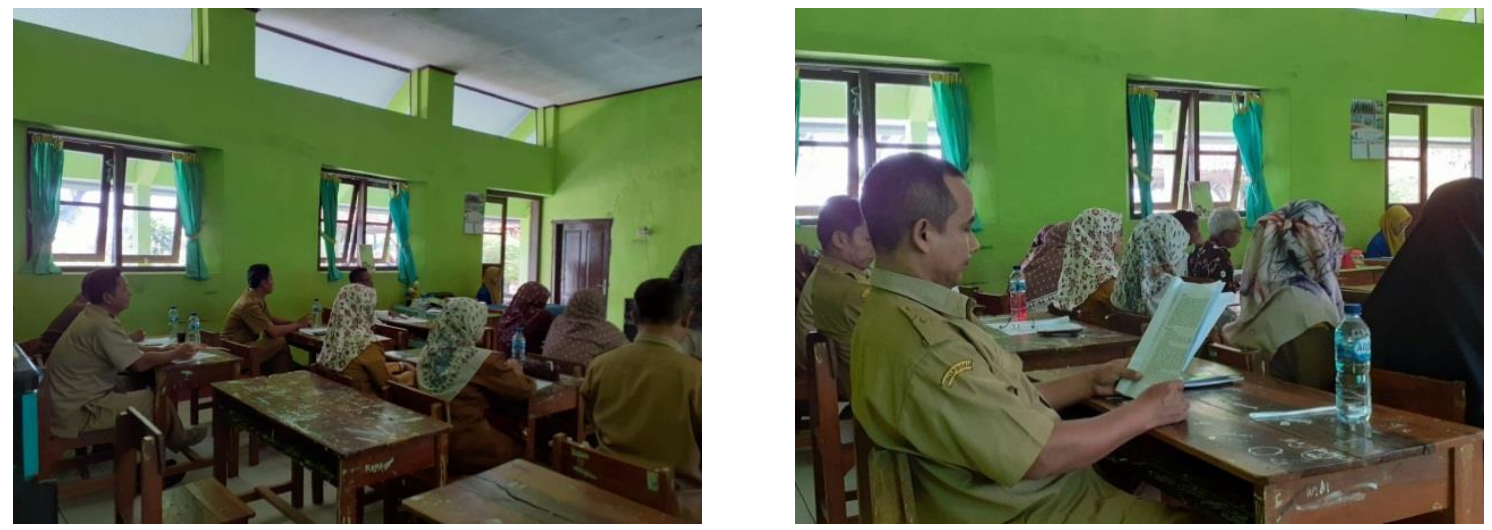

Gambar 4 Kegiatan Pelaksanaan

Setelah kegiatan pelaksanaan setiap peserta memberikan pemaparan kemudian dilakukan tanya jawab antara pemateri dengan peserta. Diskusi tampak hidup dan seluruh peserta antusias mengikuti kegiatan pelatihan. Kemudian diakhir pelaksanaan setiap peserta diberikan tugas yang harus didiskusikan mengenai kegiatan pembelajaran STEM yang akan dilaksanakan. Berikut ini salah satu contoh hasil perencanaan pembelajaran yang akan dibuat dalam bentuk bahan ajar yang dilakukan oleh guru:

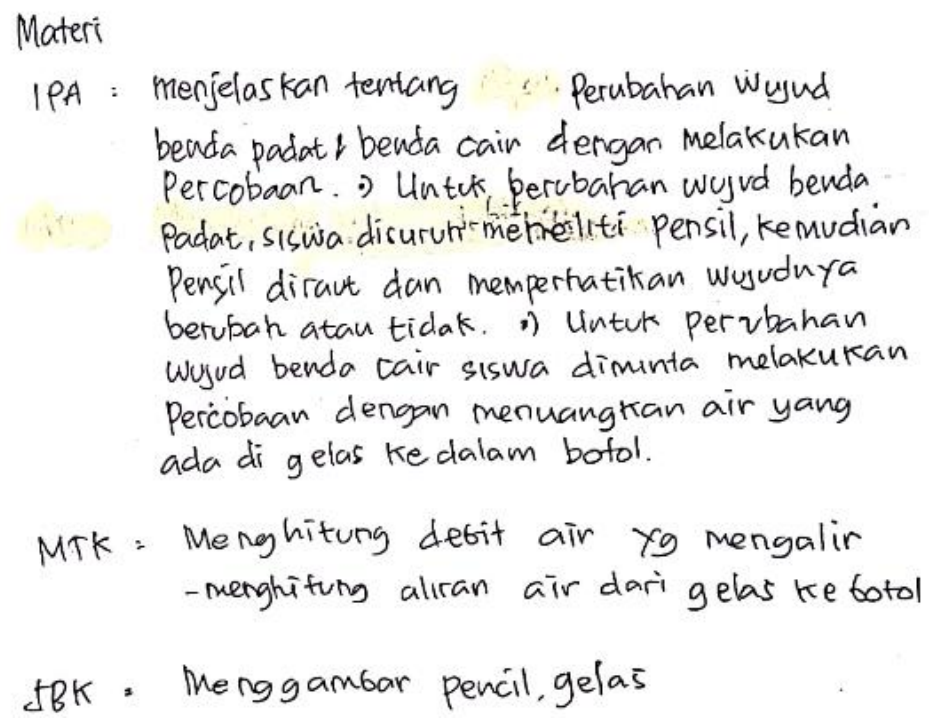

Gambar 5 Rencana Pembelajaran STEM dan Kerangka Bahan Ajar

Terlihat bahwa peserta sudah memahami dengan baik mengenai pembelajaran dengan pendekatan STEM. Hal ini dapat terlihat dari tugas yang diberikan sudah mengarah kepada pembelajaran dengan pendekatan STEM. Oleh karena itu peneliti merasa puas dengan pelaksanaan kegiatan pengabdian ini. Setelah selesai dilaksanakan proses pengabdian dilakukan evaluasi melalui kusioner yang diisi secara onlien, kesimpulan dari pertanyaan yang dijawab dapat digambarkan sebagai berikut: 


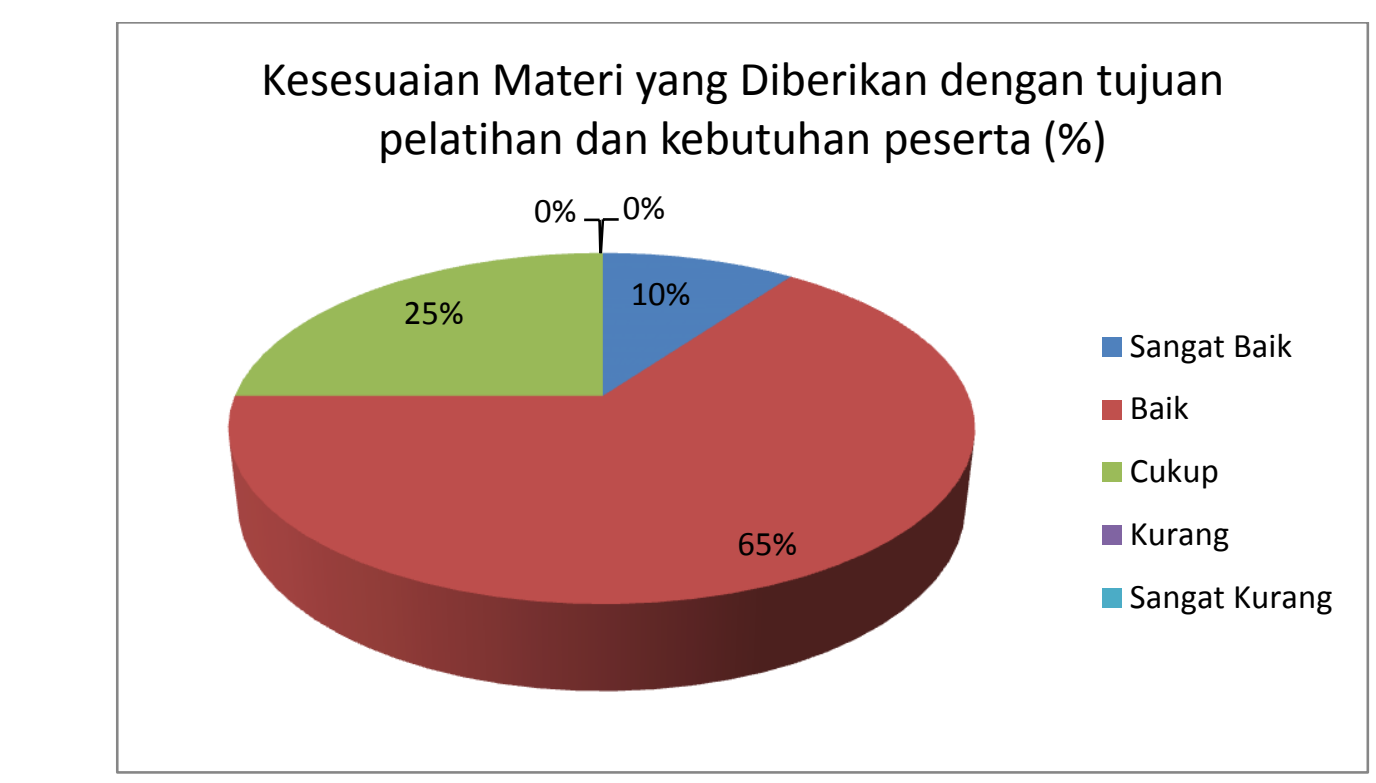

Gambar 6 Hasil Kusioner Kesesuaian Materi yang Diberikan dengan tujuan pelatihan dan kebutuhan peserta (\%)

Hasil tersebut memberikan gambaran bahwa kesusaian materi yang diberikan sudah sesuai dengan kebutuhan dan tujuan pelatihan. Hal ini ditanggapi positif oleh peserta karena peserta menganggap bahwa pelatihan ini sangat penting untuk melakukan inovasi dalam pembelajaran. Kemudian pertanyaan selanjutnya dengan hasilnya adalah sebagai berikut:

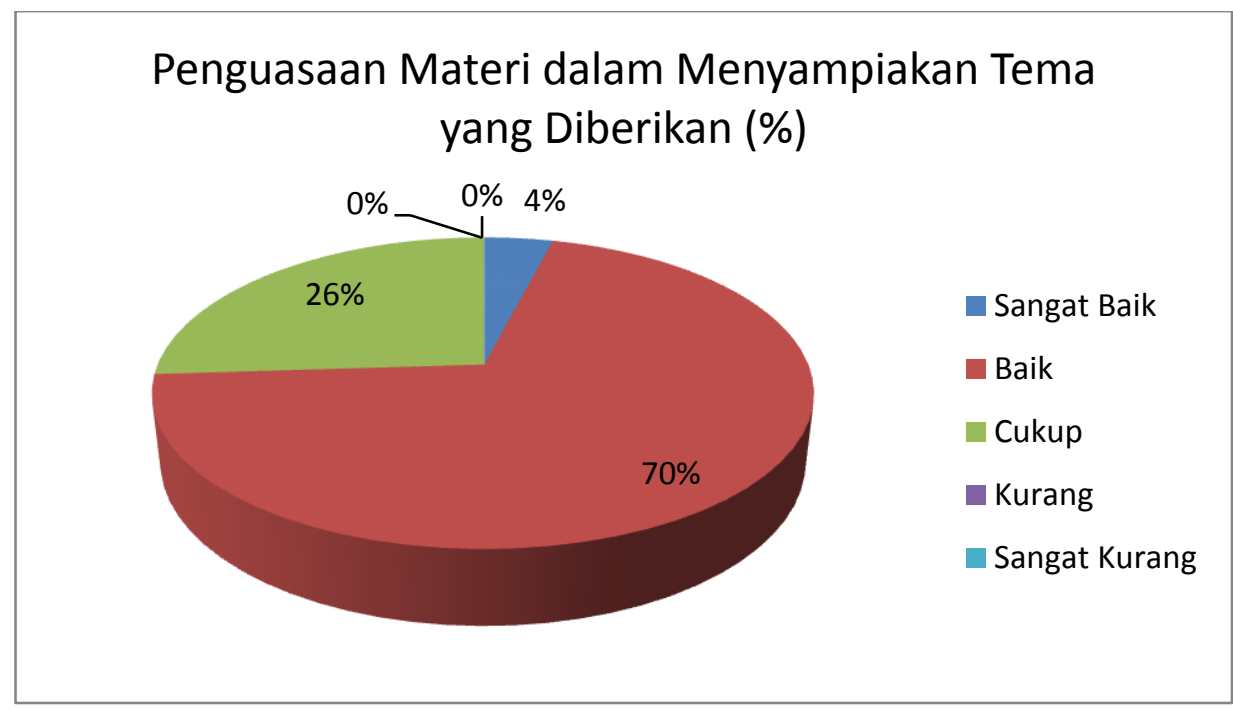

Gambar 7 Hasil Kusioner Penguasaan Materi dalam Menyampiakan Tema yang Diberikan

Kusioner ini untuk melihat apakah pemateri sudah baik dalam penyampaikan materinya, sebanyak $70 \%$ dari jumlah peserta menjawab baik dan sisanya menjawab cukup dan sangat baik. Pemateri mempersiapkan dengan baik pelatihan kali ini sehingga pelatihan dapat berjalan dengan baik. Kemudian hasil kusioner lainnya adalah sebagai berikut: 


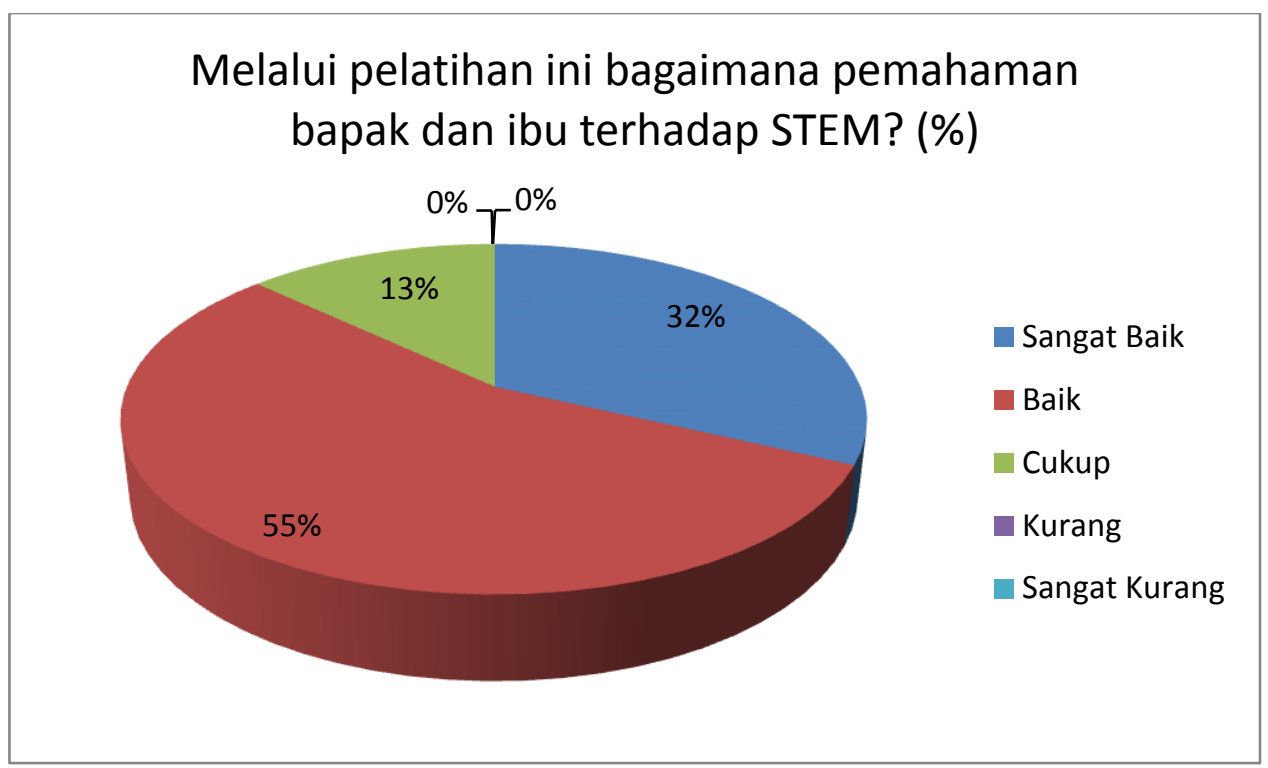

Gambar 8 Hasil Kusioner Melalui pelatihan ini bagaimana pemahaman bapak dan ibu terhadap Bahan Ajar STEM?

Hasil tersebut memberikan gambaran bahwa 32\% memilih sangat baik pemahamannya terhadap bahan ajar STEM setelah mengikuti pelatihan ini dan $55 \%$ menjawab pemahamannya baik setelah mengikuti kegiatan ini sisanya $13 \%$ menjawab cukup. Hasil tersebut memberikan pemahaman bahwa pemateri sudah memberikan penyampaikan yang baik agar peserta dapat memahami dengan baik seluruh isi materi yang disajikan. Kemudian tim juga berupaya mengungkap pendapat serta masukan setelah pelatihan ini rata-rata peserta menjawab harus ada pelatihan selanjutnya untuk mengevaluasi kegiatan STEM yang dilaksanakan di sekolah. Secara umum kegiatan berlangsung dengan baik dan peserta dapat memiliki pemahaman yang baik mengenai STEM

\section{Kesimpulan}

Kesimpulan dari kegiatan pengabdian ini adalah bahwa pembelajaran dengan pendekatan STEM dapat dilaksanakan oleh guru dengan mengkolaborasikan baik Science, Technology, Engineering, and Mathematics. Pendekatan STEM cocok untuk digunakan untuk memancing siswa agar aktif di kelas dan melakukan eksperimen dalam pembelajaran untuk menemukan konsep yang sedang dipelajari. Melalui kegiatan ini adanya peningkatan pemahaman bahan ajar STEM sebesar $32 \%$ sangat baik, 55\% baik dan sisanya $13 \%$ menjawab cukup. Kegiatan ini dapat ditindaklanjuti dengan pelatihan kegiatan evaluasi selanjutnya setelah guru melaksanakan proses pembelajaran dengan pendekatan STEM di sekolahnya masing-masing. 


\section{Daftar Pustaka}

Fadholi, T., \& Waluya, B. (2015). Analisis Pembelajaran Matematika Dan Kemampuan Literasi Serta Karakter Siswa SMK. Unnes Journal of Mathematics Education Research, 4(1).

Fitriasari, P. (2017). Pemanfaatan Software Geogebra Dalam Pembelajaran Matematika. Jurnal Pendidikan Matematika RAFA, 3(1), 57-69.

Ismayani, A. (2016). Pengaruh penerapan STEM project-based learning terhadap kreativitas matematis siswa SMK. Indonesian Digital Journal of Mathematics and Education, 3(4), 264-272.

Megasari, R. (2014). Peningkatan pengelolaan sarana dan prasarana pendidikan untuk meningkatan kualitas pembelajaran di SMPN 5 Bukittinggi. Jurnal Bahana Manajemen Pendidikan, 2(1), 636-648.

National STEM Education. (2014). TEM education network manual. Bangkok: The Institute for the Promotion of Teaching Science and Technology.

Putra, R., \& Anggraini, R. (2016). Pengembangan Bahan Ajar Materi Trigonometri Berbantuan Software iMindMap pada Siswa SMA. Al-Jabar: Jurnal Pendidikan Matematika, $\pi 1)$, 39-47.

Reeve, E. (2013). Implementing science, technology, mathematics and engineering (STEM) education in Thailand and in ASEAN. Bangkok: Institute for the Promotion of Teaching Science and Technology (IPST).

Roberts, A. (2012). A justification for STEM education. Technology and Engineering Teacher, 74(8), 1-5.

Sukmana, R. (2018). Pendekatan Science, Technology, Engineering And Mathematics (STEM) Sebagai Alternatif dalam Mengembangkan Minat Belajar Peserta Didik Sekolah Dasar. Pendas: Jurnal IImiah Pendidikan Dasar, 2(2), 189-197.

Suryadi, D. (2013). Didactical design research (DDR) dalam pengembangan pembelajaran matematika. Prosiding Seminar Nasional Matematika dan Pendidikan Matematika, 1.

Yusnita, Irda, Maskur, R., \& Suherman. (2016). Modifikasi model pembelajaran Gerlach dan Ely melalui integrasi nilai-nilai keislaman sebagai upaya meningkatkan kemampuan representasi matematis. Al-Jabar: Jurnal Pendidikan Matematika, Л1), 29-38. 